\title{
A Strategic and Hierarchical Approach to Implement a Flexible Manufacturing System (FMSs), its Scope and Applications: An Overview
}

\author{
S. C. Ram ${ }^{1}$, A. K. Mandal $^{2}$ \\ ${ }^{1}$ Department of Industrial \& Production Engineering (I.E.R.T.), Allahabad U.P. India-211002 \\ ${ }^{2}$ Department of Metallurgical Engineering (IIT-B.H.U.) Varanasi U.P. India-221005
}

\begin{abstract}
In the present scenario, the faster growth of industrial managements and technologies, it is crucial to understand that how can enhance the flexibility of a manufacturing system. So in this light, in present study, the author's has been explored a systematic approach and strategic management of an industrial process in order to become more flexible and increases the flexibility of a manufacturing system. The flexible manufacturing system (FMS) is an option because of; it consists of several integrated parts, computer control system and automated numerical control system to increase the flexibility of industrial managements and processes. The present authors look forward and analyzed that, this is possible only with the successful implementation of a FMSs body to every organization. The use of integrated parts, program instructions, data collection, transportation, automated guided vehicles (AGVs) should be hierarchically and systematically arranged. In this regard, a brief overview of successful implementation, the essential components, and structure of FMSs body have been presented. The advantages and limitations of hierarchical control of FMSs and applications areas have also been given. The aim of present overview is come to provide the right pathway to many researchers, scientists, and industrialists to facilitate the advancement and active strategic management for research and developments in industrial sectors.
\end{abstract}

Keywords: Flexible Manufacturing Systems (FMSs), AVGs, Numerical control (NC), Hierarchical and Strategic Approaches and Flexibility

\section{Introduction}

The flexible manufacturing systems (FMSs) arerepresenting a crucial part of human automated integration in the manufacturing sector, especially in automobile and aerospace industries. In the last few decades, we have found significant changes in manufacturing technology and manufacturers around the world are confronted with rapid changes in market demand. The ability to respond quickly to these changes is a key to surviving in the global competition for manufacturing system. However, due to rapid changes in technologies and increases in the flexibility, the system requires expert production philosophy to change dramatically [1].

The manufacturing technologies that comprise an FMS include, but are not limited to, NC (Numerical Control) or CNC (Computer Numerical Control) or DNC (Direct Numerical Control) machining centers, robotics, conveyors, AGVs (Automated Guided Vehicles), computers, and programmable logic controllers, etc. Apart from mentioned above statements, we need to know about FMS mean in actual from different resources. Specifically, an FMS can be defined as combinations of several NC machines and materials handling systems linked together by a common AGVs system under the guidance of a single control system. Usher and Kaber (2000) presented the needs of requirements for supervisory controllers in a Flexible Manufacturing System using GTA(Graph theoretical approach). Abdulziz m. El-tamimi et al. (2010) brought a generic concept to implement a FMSs is known as the Petri nets method. This concept is generally used to analysis and measure the performance of FMSs technology.The rapid pace of technological change has had a profound effect on manufacturing over the last several decades. In the present market scenario, the demand and specifications of newer product rapidly changes, FMSs with automation system brought this changes as quickly as possible to be able to fulfillments of market demands [2]. V. Malhotra et al. (2010) presented the merits, demerits, and applications of FMS and also concluded the reconfigurable and flexible manufacturing system is a future research [3]. Also stated that, FMS should be designed to enhance the production rate and productivity while needs to fulfilling the demand. Gupta and Buzacott (1989) presented that, the flexibility does not come from the abilities of machine alone but it is the result of a combination of several factors like physical characteristics, operating decisions, information integration, and systematic managerial approaches. Under different operating conditions, the flexibility has a critical role in providing the effectiveness to manufacturing system [4].

Bennett et al. (1992) described that, the crucial factors to the development of efficient and effective flexible manufacturing systems are (a) subsystems for effective integration (b) development of appropriate controls, and performance measures. The compatibility between organization structure and system design does argues that the flexibility cannot be potentially subjugated if its objectives are not defined and considered at design stage [5]. Neil A. Duffie, Rex S. Piper (1987) presented that a computerintegrated manufacturing systems which are the hierarchically controlled willgrow rapidly andbut it tends to become very complex because of due to their maintenances, designation, expansion, and fault tolerance are expensive[6].

As an alternative, non-hierarchical control architectures offer prospects of reduced complexity, reduced software 


\section{International Journal of Science and Research (IJSR) \\ ISSN (Online): 2319-7064 \\ Index Copernicus Value (2013): 6.14 | Impact Factor (2014): 5.611}

development costs, high modularity, high flexibility, and improved fault tolerance. These improvements are possible by locating originated information with decision making, scheduling becomes dynamic, and machines, equipments. The main focus of present overviews is to implement a FMS model with hierarchical and strategically controlled and to enhance flexibility of industrial processes. The primary objective of this study was to understand the basics of flexible manufacturing systems and recent developments in flexible manufacturing with the beginning of basics structure and components.

\section{Basic components of FMSs}

FMSs is increasingly become trends in the modern manufacturing organizations, so varieties of elements of a system needed to implement a successful structure of manufacturing systems. The essential components of FMSs are briefly explained step by step and schematically shown in figure.1 [7].

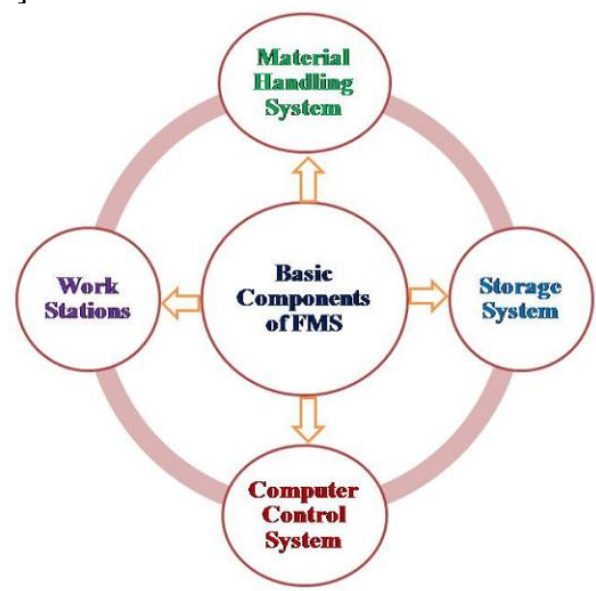

Figure 1: Basic components of FMSs [7]

\subsection{Workstations}

In FMS application, the workstations act as base components where computer numerical control (CNC) machine tools that perform the machining operation on families of parts. The various workstations are (i) Machining centers (ii) Load and unload stations (iii) Assembly centers (iv) Forging stations (v) Inspection divisions (vi) Sheet metal processing etc. In the FMSs, workstations mustbe well designed and planned to meet the demanding needs successfully of today's modern production industries.

\subsection{Material Handling and Storage System}

The various automated material handling systems are used to transport the parts related to works and subassembly parts to processing stations, sometimes the material handling system incorporated with storage systems. The various features of automated material handling and stockpiling system are (i) Random and independent movement of workparts between workstations (ii) Handling of a variety of work parts (iii) Temporary storage of work parts (iv) The accessing of loading and unloading of work parts conveniently (v) it is compatible with computer control system.

A generic FMS can handle a variety of products in small to medium sized batches and simultaneously. The flexibility of a FMS has brought to become a one of the most suitable manufacturing systems in the modern manufacturing scenario and changes the products variety with minimal life cycles. The basic concepts of flexible manufacturing systems (FMSs) understand by their high productivity, quality, and flexibility which are needed to fast response because of changing market growth demands (Womack, Jones \&Roos, 1990)[8].

The Suresh and Sridharan (2007) presented that, FMSs as a growing technology and it is mainly applicable for midvolume, mid-variety production. They were also defined FMS as an integrated production facility consisting of multifunctional numerically controlled machining centers connected with an automated material handling system [9]. The material handling system is controlled by a centralized computer system. In recent studies of modern FMSs, the researchers have been looked forward to implementsthe novel techniques to improve the performance of flexible manufacturing system (Wadhwa et al., 2005; Chan, 2003). Some scientists and researcher have used deterministic models to measure the performance recent FMSs; and these models are very crucial for estimating various parameters of system such as production rate and utilization of resources at a beginning of design stage [10-11].

\subsection{Computer control systems}

The computer control systems are an important part of implemented FMSs.In the manufacturing of more complicated parts, the system has to calculate automatically additional data points, which has been done using an interpolator. Figure 2 have shown, the Numerical Control (NC) refers to the method of controlling the manufacturing operation using directly inserted coded numerical instructions to the machine tool.

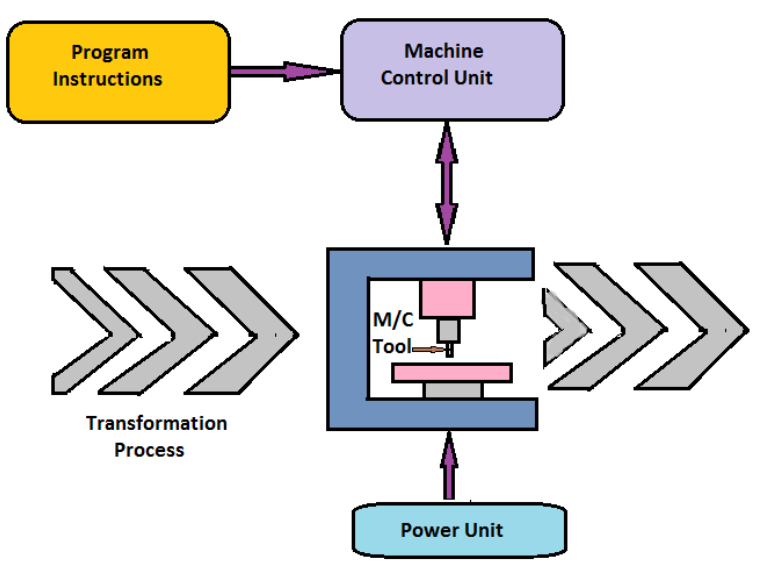

Figure 2: Numerical Control (NC) Machine Tool

\section{Structures of FMSs}

We can understand the structure of FMSs models as shown in figure 3, which is generally arranged hierarchically at a place to their functions and processes. 


\section{International Journal of Science and Research (IJSR) ISSN (Online): 2319-7064}

Index Copernicus Value (2013): 6.14 | Impact Factor (2014): 5.611

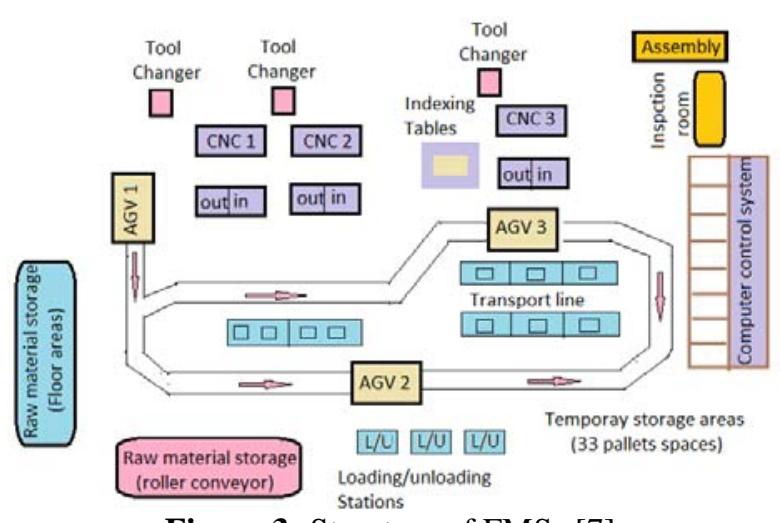

Figure 3: Structure of FMSs [7]

The information comes from figure 3; as there are several CNCs and machine tools connected along with indexing table and tool changers. The raw material storages placed in floor areas and materials transfers to machines through AVGs systems. Roller conveyor also used to move the raw materials from storage to AVGs system. The separate computer center located in floor area and the functions are automatically controls. After assembled the components of products, inspection is needed to measure the quality of the product. So Inspection and products are a crucial part of FMSs structure.

A number of literatures have been published on FMSs and several authors have given a classification of FMSs in their studies. Amongst them, the Groover (1980) [12] partitions FMSs in the following two categories:

(1) Dedicated FMS: suitable where a fixed set of parts with well-defined manufacturing requirements needed over a fixed time horizon?

(2) Random FMS: it is applicable where; the system produces a wide variety of parts in random order.

Dupont-Gatelmand (1982) [13] proposed a survey of several early FMSs in Europe, Japan and the U.S. She divides the systems in three main categories according to application of the material handling system:

(1) Flexible modules and units: that have a workstation with an automatic parts along with input/output system

(2) Flexible conveyor lines: have flexible units and connected by an automated conveyor system

(3) Unaligned flexible system: the roller conveyor is replaced by an automated Guided Vehicles (AGVs).

\section{Hierarchical approaches of FMS}

Different hierarchical approaches have been taken in to account ofimplementation of the FMS structure in a systematic manner and their meanings are explained one by one as follows.

\subsection{Manufacturing Approach}

This approach is generally applicable where productions of different parts without major retooling, and measure of processes. It is an ability of fastconversion of product from making an old line of products to produce a new product and ability to change a production schedule, to modify a part, or to handle multiple parts.

\subsection{Operational Approach}

It is ability to interchange of several operations efficiently by means of highly customized and unique products. However, for some operations, their custom ordering is arbitrary and some processes are usually determined which affixed the ordering of all operations on a particular machine (type). In this regard by keeping the routing options open and not predetermining either the 'next' operation or the 'next' machine increases. The flexibility is to make these decisions in real-time. These decisions should depend on the current system suitability (which machine tools are idle, busy, or bottleneck in currently).

\subsection{Expansion Approach}

The expansion of a system is needed depends upon it volume and module. This approach is not possible with most assembly and transfer lines. The flexibility can be measured according to how large the FMS can become. This approach is attained with: (a) a non-dedicated layout (b) non-process driven layout (c) flexible materials handling system consist of wire guided carts (d) modular and flexible machining cells with pallet changers (e) routing flexibility etc.

\subsection{Classification Approach}

The approach is generallydescribed on the basis of their function and machines used and according to use of their flexibilities. The classification of a particular FMS basically depends on mode of operation as well as the properties of the four components (e.g. workstation, materials handling, storage, and computer control systems etc.) have been explained above.

\section{Type I FMS: Flexible Machining Cell}

Flexible machining cell means the number of CNC or lathe machines center are fixed at stations and similar works to be performed on each machine tool. These machining cell are forms either single set up machine tool or multi set up tools, which are generally depend on production volume of companies. This type of FMS has related accessories e.g. pallet cart, loading/unloading and transports, storages, and shuttle cart etc. as shown in Figure 4a,4b and manufacturing activities are controlled in order to improve flexibility [4].

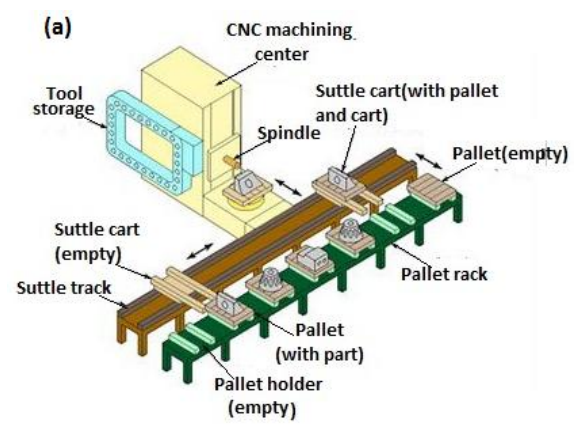




\section{International Journal of Science and Research (IJSR) \\ ISSN (Online): 2319-7064 \\ Index Copernicus Value (2013): 6.14 | Impact Factor (2014): 5.611}

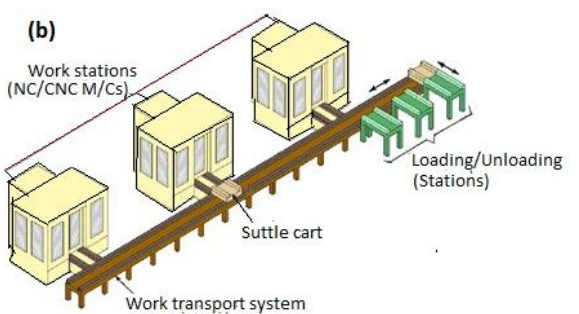

Figure 4: Flexible machining cell (a) single \& (b) multi FMC[4]

Type II FMS: Flexible Machining System

Flexible machining system has four or more work stations (typically CNC machines for machining operations or turning operations centers) and it is inter-connected mechanically by a material handling system and automatically controlby means of computer control system. The other non-processing workstation is also play as a production support but do not directly participate in the machining operations e.g. work part / work pallet stations for load/unload the jobs, and co-ordinate measuring machines also attached. These features significantly differentiate it fromFlexible manufacturing cell (FMC).

\section{Type III FMS: Flexible Transfer Line}

On assembly stations or lines, efficient material handling is crucial to transfer the works from one place to next in order to functions. Since transportation does not involve machining the item but needed to minimize the transport times with properly planned material flows, buffer sizes are decreased and thus the WIP (work in process) value reduced.

\section{Type IV FMS: Flexible Transfer Multi-Line}

In the assembly industry or at subdivisions, the workstations must be well planned and designed to meet the customer needs of modern production system. Multiline transfer systems are significantly designed as an accessory formanufacturing system. Its concept is simple by interconnecting the workstations to a transfer line you can achieve a more flexibility. From multi line transfer system, the material flow between one work stations to other substations will be controlled without hampering their characteristics such as usability or ergonomics.

\subsection{Controlling approach:}

In last, we can say that, approach should be pre-planned and controlled. Many researchers are pointed out the controlling of any manufacturing system the level of decisions cannot be made separately. If the company wants to make a decision at a certain level like business level, it should also get access the information at other levels. In whole processes of decision making, the core concept is integration [14].For this approaches a computer integration manufacturing (CIM) models has developed to control the any manufacturing systems.

\section{Significances of FMSs}

The FMS foundation was installed through worldwide in 1989 and estimated around between 500 and 1200 systems, after that, FMSs has taken a successive market demand when a system is introduced withtwo or more CNC machine tools connected by a materials handling system, and controlled by a central computer. Ranta and Tchijov [15-16] were suggested that, this machine tools number will rise to around $2500-3500$ by the year 2000 . They were also suggested that, "the strategic managements of production systems such as metal-working industries and around whole industrialized countries will be produced by similar systems [by the year 2000]." Although this was strongly contradicted 1987 by Kelley's empirical research and found that less than 5\% of those plants with computerized and automation. In most of survey of US metal-working firms ( $>1000$ firms), have FMSs and that FMS constituted only $1.5 \%$ of the total number of installations of computer numerical control and automation [17]. Among several manufacturing system, the questions arises that, why are there still only few FMS adapted in world for small-batch engineering production and it is a significant proportion of manufacturing output? There are significant practical reasons for the discrepancy between the promise of FMSs in 1980s and their narrowness as well as scarcity of application in the early $21^{\text {st }}$ century. The main reasons of suchchanges in promising developments into revolutionary FMSs are (i) improvement in basic flexibilities e.g. machine, materials handling, and storages etc. (ii) system flexibilities e.g. volume, expansion, routing etc.(iii)

\section{Flexibility and Types}

Due to reason of quick tooling, loading/unloading, and instructions, the FMS is called flexible; also it is capable of processing a variety of different parts simultaneously using material handling systems. Also, according to customer demand the quantities of productions can be adjusted easily. Generally, flexibility may be defined asthe ability of a system to respond of internal or external changes of systems without affecting its delivery time and cost. In FMSs, the uncertainty of strategic plan can create both risk and opportunities in a system, and it is with the existence of uncertainty and its flexibility becomes more valuable. When considering the problem of flexibility in the process of manufacturing systems and design, it is possible to distinguish three levels of manufacturing flexibility mentioned in next line [18-19].

\subsection{Basic flexibilities}

a) Machine flexibility: The flexibility by which a machine can possess various operations quickly.

b) Material handling flexibility: The varieties of part can be transported and replaced correctly to various machine tools in a system.

c) Operation flexibility: An alternative operation sequences can be used for a processing of jobs with the systems.

\subsection{System flexibilities}

a) Volume flexibility: This is a measure of a system capability to be operated profitably at different volumes of existing part varieties.

b) Expansion flexibility: The ability to build a system and expand incrementally.

c) Routing flexibility: This is an ability of given routing plan by which processescan adequatelyadjust for 


\section{International Journal of Science and Research (IJSR) \\ ISSN (Online): 2319-7064}

Index Copernicus Value (2013): 6.14 | Impact Factor (2014): 5.611

changes in capacity or volume through an alternative path.

d) Process flexibility: The ability of a production facility can produce a set of part types while that system facing uncertain demands.

e) Product flexibility: The size of the set of part types that can be manufactured in a system with minor setup.

\subsection{Aggregate flexibilities}

a) Program flexibility: The ability of a system to run for reasonably extended periods of time without external intervention.

b) Production flexibility: The volume of the set of part types that a system can produce without major investment in capital equipment.

c) Market flexibility: The ability of a system to adapt efficiently in accordance of changing market conditions.

\section{Strategies plan for FMSs}

Strategic plan is necessary and it should be proper approach to a successive flexible manufacturing system and used technologies. Strategy plan come and one can improve the flexibility of overall system during processing and enhanced the production rate. Well-planned strategies are developed by manufacturing society including mission statement, business strategy, marketing strategy and peoples and processes etc., enhanced the flexibility of manufacturing systems. The various strategies of FMSs can be adapted to make a strong flow of an organization with improved productivity and growth; a flow diagram has been shown in Figure 5 [20].In modern manufacturing organizations, the FMSs has implemented and applied to improve the flexibility of systems but due to lack of well design and strategic managements, therefore the industrial growths become reduced. At a results, mission and strategy plan of any processes recently become critical issues.

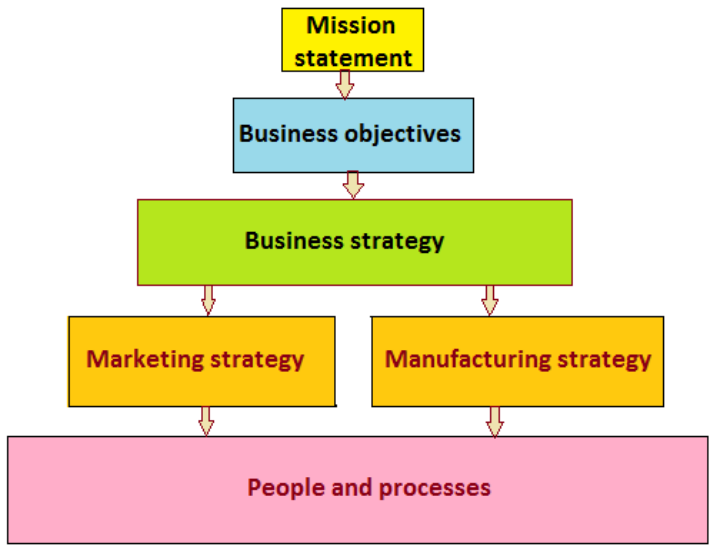

Figure 5: FMSs Strategies (reproduced from ref.20)

\section{Advantages and Limitations of FMSs}

Produce a variety of items and jobs under single shop floor or roof and enhance the productivityand it is possible with systematic implementation of FMSs. The advantages and limitations are enlisted as next lines.
A. The Advantages are

- Production rate becomes faster and quicker

- Productivity and efficiency are improved

- Improve product routing

- Improve product quality

- To reduce setup and queue times

- Product completion time reduces

- Utilize human workers better

- Serve a variety of vendors simultaneously

\section{B. Limitations}

- Skilled operator needed to handle the critical situation.

- Limited suitability to adapt to changes in product or product varieties.

- Machines are of limited capacity and the tooling necessary for products, even of the same family, is not always feasible in a given FMS.

- FMSs is generally pre-planned activity

- High cost and expensive system.

- Technological problems with component positioning and precise timing computation.

- Sophisticated manufacturing systems.

- Other problems with FMSs are; lack of technical literacy, un-strategic management, and poor implementation etc.

\section{Comparisons between hierarchical and non- hierarchical control system}

The benefits of such a hierarchical approach to system control are quite wide-ranging to understand. The control method often need for an operator to control central computer and the accompanying software. A number of researcher were described that, the variations of the basic approaches to a several of control problems [21-29]. Pioneering manufacturing work was carried out by Duffie[and Parunak. They were also explores the scheduling benefits of a distributed control system over the centralized counterpart and stations [30-31]. Dilts et al. provide an excellent review; on how can machine handle the job which is equipped with an on-board processes planner [32].In the FMS, the operating machines also has a local (cheap) bidding microcomputer which is an interfaced to the process planner and with its communicator. The machine retrofitted to $\mathrm{CNC}$ which are already in the company can be introduced.

As hierarchically controlled computer-integrated manufacturing systems grow and tend to become complicated because of due to their design ability, expandability, maintainability, and fault tolerance ability. As an alternative, non-hierarchical control architectures offer prospects of reduced complexity, reduced software development costs, high modularity, high flexibility, and improved fault tolerance. By locating decision making where information originates, global information is reduced to a minimum, scheduling becomes dynamic, machines and parts become "intelligent" entities that cooperatively interact, and the overall system is decomposes into functionally simplify, modular components [23]. 


\section{International Journal of Science and Research (IJSR) \\ ISSN (Online): 2319-7064 \\ Index Copernicus Value (2013): 6.14 | Impact Factor (2014): 5.611}

\section{Scope and Application Areas of an FMSs}

In modern manufacturing system, the flexibility has a strategic role for industrial sector that need to compete market demand competitively. Although, the ability of designing manufacturing systems whose flexibility degree is customized on the present production problem. Instead of, at the same time into account of future product evolutions and it can lead to competitive requirements. The investment to need a very high flexibility and considerably affect the cost to produce a components and flexibility may be expensive for the needs of a manufacture. The FMSs is generally implemented in sector of operation managements,and in production control planning. Moreover, FMSs is also implemented in Machining operations, Metal forming, Assembly, Joining-welding (arc, spot), gluing, Surface treatment, Inspection and Testing for materials design etc. FMSs have a crucial role in manufacturing plant to enhance the growth rate, productivity and flow of operations.

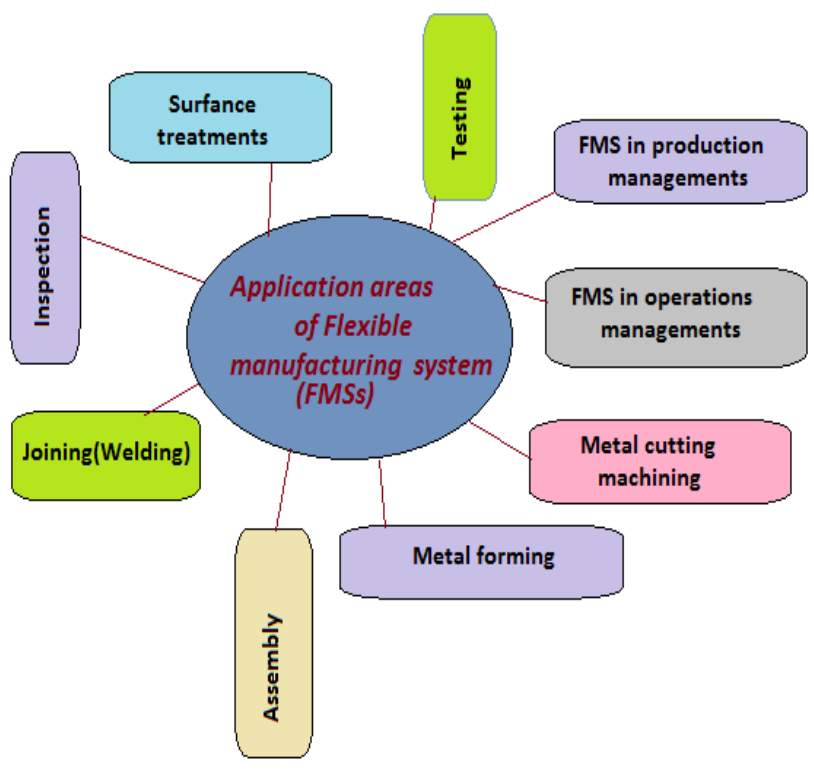

Figure 6: Applications areas of FMSs

The field of applications and scopes of FMSs has been shown in figure 6 and the various manufacturing processes which are needed a FMSs to improved their productivity and production rate. Also in rapid growth of modern industries and market competitions, it is necessary to fulfillments of customer demand quintitavely and qualitatively. Hence, FMSs are one of the beast ways with their hierarchical and strategically approaches.

\section{Conclusions}

In this context, we have seen that the implementation of FMSs model needed some basic components such as workstations, storage system, material handling system and computer control systems. Among these elements, the computer control system is considered as the heart of FMSs, because of particular operations such as tool movements, material handling, machining, work loading/unloading, metal fabrication and design is entirely controls by the computer program and data instructions. These data instructions, programming system, and industrial processes are possible through numerical control (NC, CNC and DNC) systems.
Therefore the presents study has provided a successful implementation of FMSs models, structure, hierarchically controlled systems, and strategy management. Their advantages and limitations along with applications areas have also been presented. Moreover, the various technological developments for implementation of Flexible manufacturing systems in current era have been summarized. In the current manufacturing systems, the machining operations are totally automated, where raw materials are processed into finished goods without direct intervention of an operator or labor. FMSs have taken the place of current production systems with the modern technologies and industrial processes with flexibility.

\section{References}

[1] John M. Usher and David B. Kaber. "Establishing Information Requirements for Supervisory Controllers in a Flexible Manufacturing System Using GTA".Human Factors and Ergonomics in Manufacturing, Vol. 10 (4) 431-452 (2000).

[2] Abdulziz M. El-Tamimi et al. "Analysis of performance measures of flexible manufacturing system". Journal of King Saud University Engineering Sciences (2012) 24, 115-129.

[3] Malhotra et al. "Excellent Techniques of Manufacturing Systems: RMS and FMS." IJEST,Vol. 2(3), 2010, 137-142.

[4] Gupta, D., Buzacott, JA, 1989. A framework for understanding flexibility of manufacturing systems. J. Manuf. Syst. 8 (2), 89-97.

[5] Bennett, D., Forrester, P., Hassard, J., 1992. Marketdriven strategies and the design of flexible production systems: evidence from the electronics industry. Int. J. Oper. Prod. Manag. 12 (2), 25-43.

[6] Duffie, Neil A. and Rex S. Piper, "Nonhierarchical Control of Manufacturing Systems," Journal of Manufacturing Systems, vol. 5 No.2, pp. 137139, 1986.

[7] Shivanand, H. K. Flexible manufacturing system. FMS Introduction and Description Chapter.1, books, New Age International, 2006.

[8] Womack, J. P., Jones, D. T., \&Roos, D. (1990). The machine that changed the world. New York: Rawson Associates, 11-15.

[9] Kumar, S., \&Sridharan, R. (2007). Simulation modeling and analysis of tool sharing and part scheduling decisions in single-stage multi-machine flexible manufacturing systems. Robotics and Computer-Integrated Manufacturing, 23, 361-370.

[10] Ali, M., \&Wadhwa, S. (2005). Performance analysis of partial flexible manufacturing systems. Global Journal of Flexible Systems Mgt, 6(1), 9-19.

[11] Chan, F. T. S. (2003). Effects of dispatching and routing decisions on the performance of flexible $\mathrm{mfg}$ systems. International Journal Manufacturing Technology, 21, 328-338.

[12] Groover, M.P. (1980), Automation, production system, and computer aided manufacturing, Prentice Hall, Englewood Cliffs, NJ.

[13] Dupont-Gatelmand, C. (1982), "A survey of flexible manufacturing systems, "Journal of manufacturing systems 1 (1), 1-16. 


\section{International Journal of Science and Research (IJSR) \\ ISSN (Online): 2319-7064}

Index Copernicus Value (2013): 6.14 | Impact Factor (2014): 5.611

[14] Tidd, Joseph et al. "Flexible Manufacturing Technologies and International Competitiveness". Pinter Publishers, 1991.

[15] Ranta, Jukka and IouriTchijov "Economics and Success Factors of Flexible Manufacturing Systems: The Conventional Explanation Revisited" The International Journal of Flexible Manufacturing Systems 2 (1990) pp. 169-190.

[16] Kelley, Maryellen R. "The State of Computerize d Automation in US Manufacturing". Harvard University John F. Kennedy School of Government, 1988.

[17] Sethi A.K., Sethi S.P.: Flexibility in Manufacturing: A survey. The International Journal of Flexible Manufacturing Systems, Vol. 2, No. 4, 1990, 289-328.

[18] Fulkerson B.: A Response to Dynamic Change in the Market Place. Journal of Decision Support Systems, Vol. 21, Issue 3, 1997, 199-214.

[19] United States Patent: Reconfigurable Manufacturing System Having a Production Capacity Method for Designing Same And Method for Changing its Production Capacity, Patent No.: US 6349237 B1, Date of Patent: 19th of February 2002.

[20] RajanGarg et al. "Manufacturing System: Flexibility Perspective." International Journal of Engineering Trends and Technology (IJETT) - Volume 4 Issue 6 June 2013.

[21] Fox, B R and K G Kempf, "A Representation for Opportunistic Scheduling," IEEE Conference on Robotics and Automation, pp. 111117,1985.

[22] Hatvany, J ozsef and Jozsef Janos, "Software Products for Manufacturing Design and Control," Proceedings of the IEEE, vol. 68 No. 9, pp. 10501053, September, 1980.

[23] Lewis, W., M. M. Barash , and J. J. Solberg, "Computer Integrated Manufacturing System Control: A Data Flow Approach," Journal of Manufacturing Systems, vol. 6, no. 3, pp. 177191.

[24] Lewis, William C.,"A Data Flow Architecture for Manufacturing System Control"Ph.D. Dissertation, Purdue University, West Lafayette, IN, 1984.

[25] Maley, James G. and James J. Solberg, "Part Flow Orchestration in CIM," 9th International Conference on Production Research, Cincinnati, August 1720, 1987.

[26] Parunak, H. Van Dyke, Bruce W. Irish, James Kindrick, and Peter W. Lozo, "Fractal Actors for Distributed Manufacturing Control," The Second Conference on Artificial Intelligence Applications, pp. 653660, IEEE, 1985.

[27] Vamos, T.,"Cooperative Systems based on NonCooperative People," IEEE Control Systems Magazine, vol. 3, pp.914, 1983.

[28] Agha, A "Actors: A Mo del of Concurrent Computation in Distributed Systems", MIT Press, 1986.

[29] Smith, Reid G., "The Contract Net Protocol: HighLevel Communication and Control in a Distributed Problem Solver," IEEE Transactions on Computers, vol. C29 No. 12, pp. 104113, 1980.

[30] Parunak, H. V an Dyke, "Manufacturing Experience with the Contract Net," in Distributed Artificial Intelligence, Michael M Huhns, pp. 285310, Pitman, London, 1987.
[31] Shaw, Michael J., "Task Bidding and Distributed Planning in Flexible Manufacturing," Proceedings of the 2nd Conference on Artificial Intelligence Applications, pp. 184189, IEEE, Miami Beach, Florida, 1985.

[32] Dilts, D. M., Boyd, N. P., Whorms, H. H. "The Evolution of Control Architectures for Automated Control Systems". Journal of Manufacturing Systems. Vol. 10 (1) pp. 7963.1991.

\section{Author Profile}

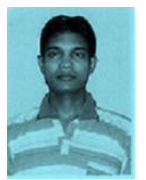

The corresponding author has done B-Tech with specialization of Industrial and Production Engineering from I.E.R.T Allahabad, M-Tech in Material Science and Engineering from MNNIT Allahabad. The author is now working as research scholar in the Department of Metallurgical Engineering IIT (BHU), Varanasi. 